\title{
ANÁLISE DO MERCADO DE PISOS DE MADEIRA LAMINADA NA CIDADE DE CURITIBA (MARKETING DE VENDAS AO CONSUMIDOR FINAL)
}

\author{
Willian Borelli Polzl ${ }^{1}$ \\ João Carlos Garzel Leodoro da Silva ${ }^{2}$
}

\begin{abstract}
RESUMO
O crescente aumento da oferta de pisos de madeira deve vir seguida do uso de instrumentos de marketing, desta forma minimizando os efeitos da concorrência por meio da diferenciação de produtos e serviços. Esta pode utilizar diferentes artifícios que permitam agregar outros valores além dos encontrados nos produto. A análise de mercado aqui apresentada está baseada no Composto de Marketing (produto, preço, promoção e distribuição). Com este ponto de vista pode-se distinguir segmentações de mercado quanto a produto, preço e serviços. Mostrando detalhes que podem ser repensados pelas empresas do ramo.
\end{abstract}

Palavras chave: Análise de mercado; Carpete de madeira; Pisos; Paraná.

\section{ANALYSIS OF WOOD FLOOR MARKET IN CURITIBA (MARKETING MIX TO SALES TO FINAL CONSUMER)}

\begin{abstract}
The incrase in wood floor supply must be followed to by marketing tools, In order to minimize the effects of competition through differentiation of products and services. Retail shops can use alternative ways to add value in their products. This paper made an market analysis using the marketing mix concept (price, product, place and promotion). This concept recommends to look the markets components and actors' interaction with respect to any product, pricing, services included, distibution details, sales promotion, payment advantages, time of delivery, professional order, etc. Showing details that give clues and insights for rethinking companies strategies in the same line (wood floor shop).
\end{abstract}

Key words: Market analysis; Residential floor; Commercial floor; Paraná.

\section{INTRODUÇÃO}

Os pisos de madeira laminada foram patenteados, em 1941, pela empresa sueca AB Gustaf Kälu, tratando-se de uma lâmina de madeira nobre sobre um corpo de madeira de espécies menos nobres (MEDEIROS, 1995).

Estes produtos somente chegaram ao Brasil, em meados da década de 70, com a fábrica da Atlantic Venner do Brasil. No Paraná a pioneira foi a fábrica da Wiegando Olsen. O comércio de pisos de madeira teve um impulso com o declínio no uso de carpetes e seus similares, porém conta com a atual concorrência de outros tipo de pisos, principalmente os vinílicos.

Com o plano real e conseqüente equivalência da moeda Brasileira ao dólar Norte Americano (a partir de 1994), ocorreu uma grande entrada de novas marcas, principalmente européias.

Estas marcas comercializam principalmente pisos com superfície sintética (lâmina melamínica) também conhecidos como sendo pisos alto tráfico (AT). Já, nos pisos nacionais, predominam as superfícies naturais (lâminas de madeira de lei) em geral chamados de pisos naturais ou laminados. Os corpos dos pisos são compostos principalmente

\footnotetext{
${ }^{1}$ Willian Borelli Polzl, - Eng. Florestal, Mestrando em Economia Florestal da UFPR. wpolzl@ floresta.ufpr.br

2 João Carlos Garzel Leodoro da Silva, - Eng. Florestal, Professor Dr. do Curso de Eng. Florestal da UFPR. garzel@floresta.ufpr.br
} 
por painéis de fibra de madeira do tipo MDF (Medium Density Fiberboard), em uma versão chamada HDF (High Density Fiberboard), mas existem ainda pisos com estrutura do tipo aglomerado e compensado, predominando a madeira de Pinus e Eucalyptus, proveniente de reflorestamento como sendo a matéria prima mais utilizada em suas estruturas (corpo).

O mercado de pisos de madeira é responsável por uma grande quantidade de empregos e por uma movimentação expressiva de renda, para tanto é de suma importância a sua melhor compreensão e 0 seu desenvolvimento.

\section{OBJETIVOS}

O objetivo principal deste trabalho é fornecer subsídios a respeito do mercado de pisos de madeira laminada na cidade de Curitiba, utilizando ferramentas de Marketing para a delimitação de parâmetros mercadológicos:

- Observar características de produtos;

- Observar características de preço;

- Observar características de distribuição e

- Observar características de promoção.

\section{REVISÃO BIBLIOGRÁFICA}

\section{Conceito de Composto de Marketing}

"Composto de Marketing é o conjunto de ferramentas que a empresa usa para atingir seus objetivos de marketing no mercado alvo" (KOTLER, 1998). Dentro dos diversos instrumentos que podem ser usadas no composto de marketing, os itens principais são os "4 Ps" (segundo o conceito em inglês), podem ser ditos como sendo os principais: a) produto; b) preço; c) promoção e d) distribuição (place).

\section{Produto}

O produto, inclui qualidade, "design", características, marcas e embalagens. Como parte de sua oferta de produto, podem ser oferecidos serviços complementares. Paralelamente, os consumidores esperam a satisfação de suas necessidades e desejos.

Segundo LELE (1983), citado por KOTLER (1998), dentre as variáveis que mais incomodam os usuários, no pós-venda são: a) freqüência de avarias; b) demora para os consertos a serem feitos e c) custo com estas manutenções.

Para um mercado de ampla concorrência, as empresas que fabricam um bom produto, mas fornecem serviços ruins por parte de revendedores, estão em grande desvantagem, pois em geral um cliente não está comprando apenas um produto (pisos de madeira), está comprando também a confiabilidade do produto, a destreza e arte do instalador, a prontidão dos serviços de reparo (caso sejam necessários), o "status" e o prestígio de ter um piso de madeira (SINCLAIR, 1992).

Para BARRY (1991) citado por KOTLER (1998), os serviços devem estar fundamentados basicamente nesta ordem decrescente de itens: a) confiabilidade ou habilidade de desempenhar o serviço prometido com segurança e precisão; b) disposição em ajudar os consumidores e em fornecer serviços rápidos; c) segurança (conhecimento); d) na cortesia dos funcionários e habilidade em inspirar confiança e responsabilidade; e) empatia ou cuidado e atenção, individualizada aos consumidores e na tangibilidade ou aparência das instalações físicas, equipamentos, funcionários e materiais de comunicação.

A garantia é eficaz principalmente no caso do produto/empresa não ser muito conhecido ou para casos onde a qualidade é superior a dos concorrentes. Pode ser um chamariz para as vendas, mas não se deve garantir o que não se pode cumprir sob pena de complicações na logística, na administração da empresas e problemas judiciais.

As principais desvantagens dos pisos de madeira maciças (tábuas corridas ou frisos), em comparação aos pisos de madeira laminada é que aqueles necessitam ou de um contrapiso com barrotes de madeira a cada $35 \mathrm{~cm}$, ou podem também ser fixados diretamente no piso de cimento através de parafusos e buchas ou colados no piso cimentado. Após 7 a 15 dias da instalação, é necessária a raspagem, calafetação e envernizamento (3 demãos) do assoalho. A secagem e cura completa se dá após mais 7 dias (VEIGA, 1997). Por outro lado o piso de madeira laminada não é colado ao chão, não sendo necessário cimentar ou fazer obras no chão, necessitando de 1 a 2 dias 
para secar colas e firmar o material definitivamente.

Os principais problemas técnicos encontrados pelos usuários, segundo MEDEIROS (1995) eram: a) Instalações mal feitas; b) Encaixes defeituosos; c) Mudanças na tonalidade do piso quando exposto ao sol; d) Pouca resistência à ação de sapatos de salto fino e móveis pesados, além do e) Aparecimento de frestas.

Não havia normas sobre a fabricação de pisos laminados de madeira até 1995 . Até aquele momento todas as normas não passavam de um documento do IPT (Instituto de Pesquisas Tecnológicas) chamado de Referência Técnica, baseada nas normas técnicas Francesas e Norte Americanas (MEDEIROS, 1995)

Uma pesquisa realizada pelo Sindicato da Indústria de Construção Civil do Estado do Paraná, SINDUSCON-PR (2000), aponta que a colocação de piso laminado de madeira na sala de residências é uma vontade de $28 \%$ dos potenciais compradores de imóveis da classe A na Região Metropolitana de Curitiba, 28\% na classe social B1 e 19,33\% na classe social B2. Também foi perguntado o que os consumidores em potencial consideram menos importante, os pisos de madeira laminada obtiveram $20 \%$ de recusa na classe A, $17 \%$ na classe B1 e 16,67\% na classe B2. Outra pergunta foi, quais seriam as condições mínimas em uma casa ou apartamento, $12 \%$ da classe A respondeu que o piso laminado de madeira seria o mínimo, na classe $\mathrm{B} 1,7 \%$ falaram que este seria o mínimo e $6,67 \%$ da classe B2.

Em CASA CLAUDIA (2000), acompanhou-se uma instalação de pisos laminados de madeira em uma apartamento com dificuldade padrão na colocação e observou a necessidade de dois dias de trabalho para uma obra de $44 \mathrm{~m}^{2}$, segundo os instaladores a média é de $30 \mathrm{~m}^{2}$ de pisos instalados por dia.

\section{Preço}

Este item é uma ferramenta crítica do composto de marketing, pois esta indica a quantidade de dinheiro que os consumidores pagam por um produto, representando o custo para o consumidor. Relacionados ao preço estão envolvidos descontos e reduções (em diferentes níveis) e variações nas formas de pagamento.

Segundo KOTLER (1998), o preço é o único elemento do composto de marketing que produz receita, os outros elementos geram custos, sendo também um dos elementos mais flexíveis do composto de marketing porque pode ser rapidamente modificado.

Esta rápida mobilidade, reflete a sensibilidade característica do preço. Segundo NAGLE \& HOLDEN (1995), há nove fatores influenciadores das mudanças no preço, os compradores são menos sensíveis a preços;

- quando são menos conscientes da existência de produtos substitutos;

- quando o produto for mais exclusivo;

- não podem facilmente, comparar a qualidade dos produtos substitutos;

- quanto menor a despesa em relação a sua renda total;

- quanto maior o benefício final do produto;

- quando parte do custo do produto for dividido com outro produto;

- quando o produto é mais utilizado em conjunto com ativos previamente comprados;

- quando o produto apresenta mais qualidade, prestígio ou exclusividade;

- quando não podem estocar o produto.

Para a definição do preço final de um produto podem ser utilizadas estratégias de adaptação de preço, tais como: a) preços geográficos; b) descontos para pagamento a vista; c) desconto por quantidades; d) descontos funcionais; e) descontos sazonais e concessões promocionais; f) preços promocionais; g) preços de ocasião; h) cupons de desconto; i) prazos de pagamento maiores; j) diferenciação de mercado, variando o preço do produto através da forma do produto, localização ou tempo; k) preços reduzidos para a aquisição de linhas de produtos e l) características opcionais ou pacotes de subprodutos (KOTLER, 1998).

Segundo estudos feitos pela American Marketing Association citado por SMITH (1998), as técnicas de determinação de preço mais utilizadas na indústria Norte Americana são: preço baseado na concorrência (> 50\%); preços baseados no custo de produção (> 25\%) e o preço baseado na demanda ( $>15 \%$ ).

Em relação ao preço, em 1995, o piso de madeira laminada era de $40 \%$ a $60 \%$ menor que o preço do piso de madeira corrida (piso 
de madeira maciça), hoje o preço dos produtos não tem tanta diferença, pois as empresas de pisos de madeira maciça desenvolveram produtos mais baratos embora a qualidade também tenha caído (MEDEIROS, 1995).

No mercado da Grande São Paulo a relação entre os preços do metro quadrado instalado dos piso laminados de madeira (carpete de madeira), pisos laminados de alta resistência e pisos de madeira maciça obedecia a seguinte relação: carpete de madeira de $\mathrm{R} \$$ 55,00 a $\mathrm{R} \$$ 60,00 (Novopiso), Laminado de alta resistência de $\mathrm{R} \$ 30,00$ a $\mathrm{R} \$ 70,00$, madeira maciça de $\mathrm{R} \$ 55,00$ a $\mathrm{R} \$ 95,00$ (Indusparquet) (CASA CLAUDIA, 2000).

\section{Promoção}

Para KOTLER (1998), promoções são todas as atividades desempenhadas pela empresa para comunicar e promover seus produtos junto ao mercado alvo.

BUSH (1998), comenta que similarmente ao Composto de Marketing (Marketing Mix) há o "promotion mix" o qual é composto pela: a) propaganda, b) vendas pessoais, c) promoções de venda e d) pela publicidade.

Segundo BROWN (1974), citado por KOTLER (1998): A propaganda oferece uma razão para a compra e a promoção oferece um incentivo à compra. As promoções trazem respostas mais rápidas e mensuráveis em termos de vendas que a propaganda; as promoções de venda tendem a trazer novos compradores a longo prazo nos mercados maduros porque atraem principalmente aqueles que buscam ofertas compensatórias, que trocam de marca à medida que surgem melhores ofertas. Os compradores leais à marca tendem a não alterar seus padrões de compra em função de marcas concorrentes; tudo indica que a propaganda é capaz de aumentar a lealdade de marca; as promoções são responsáveis por saltos nas quantidades vendidas que nem sempre se mantém constantes.

GAGNON \& ADAMS (1999), citam que para o mercado de painéis de cimento madeira Norte Americanas, os métodos de propaganda que garantem maior aumento nas vendas são: a) catálogos esquemáticos; b) representantes comerciais; c) sistema de correspondência; d) participação em eventos e demonstrações; e) anúncios em jornais. Os métodos com menos retorno são: a) Distribuição de Kits; b) Anúncios na internet; c) Anúncios em TV e rádio e d) Doações a entidades de caridade.

\section{Distribuição}

A distribuição inclui as várias atividades assumidas pela empresa para tornar o produto acessível e disponível aos consumidores alvos. Na distribuição estão envolvidos: o ponto de venda; cobertura da distribuição; canais de distribuição; zonas de venda; níveis de venda; locais de estoque; rotinas para o transporte, entre outras.

Para KOTLER (1998), o comércio varejista pode ser visto por lojas físicas e lojas virtuais (compras por catálogo, televisão, internet), nas lojas propriamente ditas podem ser vistas situações onde a variação na interação dos clientes com os funcionários é fundamental, no lado menos pessoal há as lojas de auto-serviço e no oposto estão as lojas de serviço completo.

Em um estudo feito por VLOSKY (1999), foi qualificado o uso do "Ebusiness" (internet, intranet $\mathrm{e}$ extranet) no setor madeireiro norte americano sendo que a sua utilização pode ocorrer principalmente para: contatar consumidores; mostrar produtos via "home page"; fechamento de contratos; promoção de produtos; consulta sobre produtos e preços; vendas eletrônicas (ecommerce); atividades de administração; fonte de informação interna; gerenciamento de inventários e logística.

Cada tipo de mercadoria a ser vendida tem uma interação vendedor/cliente própria esta relação aumenta com o maior valor agregado ou maior lucro unitário, demandando um local diferenciado para o atendimento do cliente, funcionário e serviços individualizados, brindes, facilidades.

O processamento do pedido é o início da logística de entrega, quanto maior o número de etapas desde este processamento até a entrega do produto menor será a satisfação do cliente e o lucro da empresa, (KOTLER, 1998).

A armazenagem é uma artimanha para evitar problemas com variações de consumo, produção ou preço. Manter um estoque envolve pessoal, local próprio e transformação 
de capital ativo em passivo. Um controle de estoques eficiente denota um conhecimento bastante grande das sazionalidades do mercado

Sempre que há uma entrega de produto a ser feita, há a necessidade de transporte, uma rede de entregas sempre será necessária para produtos "físicos", sendo necessário ajustar problemas com trânsito, com a fragilidade do produto, a pontualidade, custos com manutenções, sempre observando a margem de lucro desejada, (HAMMETT, 1998)

\section{MATERIAL E MÉTODO}

O presente trabalho foi realizado através de coletâneas de endereços de empresas que comercializavam pisos de madeira em 1997, 1998 e 1999 (Junta comercial, listas telefônicas, anúncios em jornais, revista, televisão e publicidade de rua).

Foi tomado como área de estudos, o Município de Curitiba, estado do Paraná, cidade esta com 1.400.000 habitantes, cidade polo da Região Metropolitana de Curitiba e eminente metrópole regional.

Após esta estimativa, realizada em setembro de 1999, houve uma escolha aleatória de 9 empresas, o que correspondia a 20\% das empresas existentes na época (47 empresas), tendo sido realizada uma visita e aplicado um questionário padrão com perguntas divididas em cinco áreas: Informações gerais: produto; preço; promoção e distribuição.

Um total de 23 empresas (50\%), foram contatadas via telefone, em dois momentos, o primeiro em setembro de 1999 e o segundo em março de 2000, objetivando saber se ainda trabalhavam com pisos de madeira, saber as marcas e modelos de pisos comercializados e os seus preços.

Os dados relativos a preço foram analisados estatisticamente, através de seu coeficiente de variação (CV) e de suas médias aritméticas.

Os telefonemas, a análise dos questionários e das informações passadas oralmente, bem como as impressões pessoais do entrevistador formam o subsídio para a elaboração deste artigo.

Deve-se salientar que muitas informações obtidas, correspondem a opinião ou a expectativa das pessoas entrevistadas, sendo uma possível fonte de distorções nos dados.

\section{RESULTADOS}

\section{Produto}

Existem muitos produtos similares no mercado, com a mesma finalidade, sendo denominados como pisos de madeira laminada. Em regiões do Brasil ocorre sinônimos, dentre estes sinônimos podem ser citados: a) pisos laminados de madeira; b) pisos de madeira laminada; c) pisos ecológicos; d) carpetes de madeira; e) pisos alto tráfego, f) pisos flutuantes.

Os produtos ditos como pisos laminados de madeira possuem muitas diferenças "específicas", basicamente ocorrem pisos laminados que possuem a camada superior com madeira (natural) e pisos com acabamento melamínico de alta pressão ou similar (sintético), embora ambos sejam montados sobre um painel de madeira com espessura variável (em torno de $7 \mathrm{~mm}$ ), é esta lâmina superior e o seu acabamento que confere a utilização do piso e o seu preço.

Outra característica importante é que estes pisos de madeira laminada, são instalados sobre o pavimento de cimento sem ser nele fixado, eles ficam "flutuando" sobre camadas de isolantes e o próprio cimento.

As empresas podem ser separadas pela quantidade vendida. São encontradas empresas com vendas mensais menores que $999 \mathrm{~m}^{2} /$ mês (pequenas empresas), entre $1.000 \mathrm{~m}^{2}$ e 2.999 $\mathrm{m}^{2} /$ mês (médias empresas) e empresas com vendas superiores a $3.000 \mathrm{~m}^{2} /$ mês (grandes empresas), Tabela 1.

Em alguns casos as empresas trabalham com outros produtos, e sendo assim, apesar de terem grandes vendas no geral, são definidas como pequenas na venda específica de pisos laminados.

As empresa que hoje possuem maiores fatias do mercado de pisos de madeira em Curitiba trabalham com estes produtos em geral já a mais de 7 anos, as empresa médias comercializam entre 4 e 7 anos, as menores estão a menos de 4 anos no ramo, tabela 1 . 
Tabela 1 - Classificação das empresas varejistas de pisos laminados de madeira em Curitiba, por volumes vendidos (M3/ Mês) e tempo atuando no ramo (anos).

\begin{tabular}{cc|c|c|c|}
\hline Classificação & $\begin{array}{c}\text { Quantidades vendidas } \\
\left(\mathrm{m}^{3} / \text { mês }\right)\end{array}$ & $\begin{array}{c}\text { Porcentagem } \\
(\%)\end{array}$ & $\begin{array}{c}\text { tempo de atuação } \\
(\text { anos })\end{array}$ & $\begin{array}{c}\text { Porcentagem } \\
(\%)\end{array}$ \\
\hline Pequena & $<999$ & 44 & $<4$ & 52 \\
Média & 1000 a 2999 & 35 & 4 a 7 & 37 \\
Grande & $>3000$ & 21 & $>7$ & 11 \\
\hline
\end{tabular}

Existem empresas que buscam abordar apenas o público mais seleto e o de melhor renda, melhorando a aparência geral da loja, pessoal bem preparado para recepção e vendas, bom nível de requinte do ambiente e conforto para o cliente, bem como a instalação de pontos comerciais em bairros de classe social abastada, para tanto estas lojas oferecem pisos importados em geral alto tráfico e com preços "premium" para estes produtos.

A tabela 2 mostra uma relação da grande maioria das marcas de pisos de madeira encontradas em Curitiba bem como as suas procedências

Tabela 2 - Marcas de pisos de madeira e suas procedências, com revenda em Curitiba (1999)

\begin{tabular}{ll|l}
\hline & Pisos Importados & \multicolumn{1}{c}{ Pisos Nacionais } \\
FABRICANTE & PROCEDÊNCIA & \\
Lamett & (Holandês) & Eucafloor \\
Poliface & (Português/ Brasileiro) & Durafloor \\
Sprella & (Alemão) & Trevo Piso \\
Carpiso \\
Pergo & (Sueco) & Formilaine \\
Eurofloor & (Austríaco) & Novo Piso \\
HBM & (Alemão) & Ouro Piso \\
Fleder & (Alemão) & InterLínea \\
& & Inatapiso \\
& & Lammy \\
\hline
\end{tabular}

Algumas das marcas européias, possuem estoques e representações apenas em São Paulo, para determinadas marcas a importação têm de ser direta e em grandes quantidades, dificultando em ambas as situações a assistência técnica de fábrica e aumentando o tempo de entrega dos produtos.

As marcas nacionais apresentam uma grande quantidade de modelos de pisos de madeira com revestimento em lâminas de madeira de lei (90\%), também sendo encontrada algumas possibilidades em revestimento sintético.

Dentre as empresas que atuam no comércio de pisos de madeira em Curitiba, existem aquelas, que apenas vendem para o consumidor final (representando 80\%), e empresas que revendem para comerciantes menores, além de atenderem no varejo. Estas empresas com maior quantidade de vendas conseguem maior giro de capital e maiores descontos junto as fábricas de pisos, representando cerca de $20 \%$ das empresas que atuam em Curitiba.

Uma certa relação pode ser encontrada entre o tamanho das empresas e o número médio de funcionários: As empresas grandes possuem aproximadamente 9 funcionários fixos entre vendedores e administrativos e equipes de 10 a 30 instaladores dependendo da época do ano. As empresas médias tem 6 funcionários fixos e de 8 a 20 instaladores: As pequena empresas 4 funcionários fixos e 2 a 10 instaladores, conforme tabela 3. 
Tabela 3 - Número médio de empregados por classe de empresa.

\begin{tabular}{c|c|c}
\hline Classificação da Empresa & $\begin{array}{c}\text { Número de Empregados } \\
\text { (administrativo e vendedores) }\end{array}$ & $\begin{array}{c}\text { Número de Instaladores } \\
\text { (Instaladores) }\end{array}$ \\
\hline Pequena & 4 & 2 a 10 \\
Média & 6 & 8 a 20 \\
Grande & 9 & 10 a 30 \\
\hline
\end{tabular}

Existe uma grande dificuldade em definir o número de pessoas que atuam com a venda ou instalação de pisos de madeira, pois muitas empresas comercializam outros produtos além de pisos, tais como: carpete; forrações; pisos maciços; material de acabamento em geral. Bem como pela sazonalidade nas vendas, que crescem nos meses de Setembro até Dezembro e diminuem durante os meses de férias escolares (Janeiro, Fevereiro, Junho, Julho).

Devido a grande amplitude nos preços dos pisos de madeira, bem como na qualidade, os consumidores mais constantes são os das classes sociais com ganhos acima de 11 salários mínimos (R\$1.500,00/ mês, salário de março de 2000).

Pelo fato do perfil do consumidor ser mais de usuários residenciais, é bem maior a variedade de marcas neste segmento de pisos, do que modelos de alto tráfego.

Em muitas empresas (cerca de 60\%) é exigido exclusividade no serviço de instalação dos pisos (principalmente nas empresas grandes), em outras empresas é admitido o repasse de trabalho entre instaladores (onde surge a figura de "intermediários", os quais gerenciam os serviços para uma equipe de colocadores a ele vinculada).

Para ser aceito como instalador nas empresas maiores é necessário experiência comprovada, entrando assim em um estágio dito "probatório" que dura de 3 a 5 meses, onde ele se atualiza com os produtos e procedimentos da fábrica de pisos e da empresa comerciais. Somente após isto o instalador é aceito e executa trabalhos sozinho

\section{Preço}

O item preço foi estudado em dois períodos. Sendo que um levantamento dos preços, em 50\% das empresas foi realizado em setembro de 1999 e outro, semelhante foi realizado em março de 2000, dando origem as tabela 4 e 5. Nelas são colocadas as variações no preço dos pisos importados e dos pisos nacionais no período (6 meses) respectivamente.

Os preços médios dos pisos nacionais atualmente (março 2000), variam de $\mathrm{R} \$ 22,00 /$ $\mathrm{m}^{2}$ (Inatapiso) até $\mathrm{R} \$ 50,00 / \mathrm{m}^{2}$ (Novo Piso, Export), os preços médios dos pisos importados variam de $\mathrm{R} \$ 32,00 / \mathrm{m}^{2}$ (HBM, modelo 1) até $\mathrm{R} \$ 78,00 / \mathrm{m}^{2}$ (Pergo, Select).

Existe no mercado o costume de se vender pisos laminados de qualidade inferior "pisos comerciais", estes possuem defeitos estéticos em geral, sendo usados como artifício promocional, pois o seu preço pode ser mais baixo, podendo chegar a $\mathrm{R} \$ 19,90 / \mathrm{m}^{2}$. Um exemplo é o piso Lammy com preço "extra" de $\mathrm{R} \$ 28,90 / \mathrm{m}^{2}$ e preço “comercial” de $\mathrm{R} \$ 23,00$ $/ \mathrm{m}^{2}$ (20\% de diferença).

Os preços encontrados nas tabelas $4 \mathrm{e}$ 5, obedecem as seguintes características: São para produtos colocados; em algumas empresas este preço não possui o material básico de montagem, tais como mantas, juntas de dilatação, etc.; em geral estes preços não incluem o material de acabamento como rodapés, passagens de porta, cantoneiras, etc..

Os pisos laminados importados apresentam preços médios superiores a $\mathrm{R} \$$ $30,00 / \mathrm{m}^{2}$. No caso dos pisos da Lamett, os seus produtos pararam temporariamente de serem vendidos no Brasil, sendo um dos motivos para a queda do seu preço. Dentre os preços médios ( março de 2000) dos pisos importados pode ser observado, há existência de dois patamares de preços, um entre $\mathrm{R} \$$ $32,00 / \mathrm{m}^{2}$ e $\mathrm{R} \$ 38,00 / \mathrm{m}^{2}$ e outro entre $\mathrm{R} \$$ $53,50 / \mathrm{m}^{2}$ até $78,00 / \mathrm{m}^{2}$.

Alguns pisos apresentaram uma redução nos seus preços durante o período, dentre eles o piso fabricado pela Interlínea com redução de 42,26\%. Também os modelos fabricados pela Ouropiso, onde o modelo Sintético $(7 \mathrm{~mm})$ apresentou uma redução de $24,86 \%$, e o modelo Natural $(7 \mathrm{~mm})$ teve redução de $21,86 \%$. Outro modelo que teve seu preço reduzido foi o Trevo Piso AR com $22,05 \%$. 
Outra característica é a atual amplitude de preços das empresas para o mesmo modelo de piso (verificado pelo Coeficiente de Variação), em casos a amplitude dos preços chega a 17,85\% (Eucapiso), onde foi encontrado intervalo de $\mathrm{R} \$ 19,90 / \mathrm{m}^{2}$ até $\mathrm{R} \$$ $29,90 / \mathrm{m}^{2}$.

Existem grandes variações nos preços dos pisos de madeira laminada fabricados no Brasil, durante o período de 6 meses compreendido entre setembro de 1999 e março de 2000. Os produtos que tiveram maiores aumentos de preços foram: Trevo piso, ATN $(53,71 \%)$; Trevopiso, Hitech $(46,84 \%)$ e Durafloor, Home $(42,78 \%)$.
O Preço médio da colocação é de R\$ $3,25 / \mathrm{m}^{2}$, preço máximo $\mathrm{R} \$ 10,00 / \mathrm{m}^{2}$ para obras difíceis que necessitem nivelamento de piso. O preço mínimo $\mathrm{R} \$ 2,00 / \mathrm{m}^{2}$, em geral é oferecido pelas empresas com grande volume de vendas (mais de $3.000 \mathrm{~m}^{2} /$ mês). Cerca de 90\% das empresas comerciais de pisos em Curitiba empregam instaladores tercerizados, os quais ganham por metro quadrado colocado.

Outra característica interessante referese a colocação de pisos em escadas, nestes casos o serviço é cobrado por degrau, onde há grande variação de preço (R\$ 16,00 até mais de $\mathrm{R} \$ 50,00)$, dependendo das características da escada.

Tabela 4 - Listagem dos modelos de pisos de madeira importados vendidos pelas lojas de Curitiba. Preços, média e coeficiente de variação dos preços entre os mês de setembro de 1999 e março de 2000.

\begin{tabular}{|c|c|c|c|c|c|c|c|}
\hline \multirow[t]{2}{*}{ Fabricante } & \multirow[t]{2}{*}{ Modelo } & \multicolumn{2}{|c|}{ Setembro 1999} & \multicolumn{2}{|c|}{ Março 2.000} & \multicolumn{2}{|c|}{ Variação } \\
\hline & & Média & C.V. & Média & C.V. & **** & \\
\hline Eurofloor & & 35,00 & 11,36 & 36,00 & * & 1,00 & 2,78 \\
\hline Eurofloor & & 44,00 & 3,45 & & & & \\
\hline Fleder & & & & 34,00 & * & & \\
\hline HBM & Modelo 1 & & & 32,00 & * & & \\
\hline HBM & Modelo 2 & & & 38,00 & * & & \\
\hline Lamett & Saxon & 61,50 & ** & 37,00 & 3,82 & $-24,50$ & $-66,22$ \\
\hline Lamett & Classic & 48,00 & * & & & & \\
\hline Pergo & Original & 74,00 & 17,73 & 61,85 & 2,62 & $-12,15$ & $-19,64$ \\
\hline Pergo & Family & 40,25 & * & 53,50 & 14,54 & 13,25 & 24,77 \\
\hline Pergo & Select & 48,00 & $*$ & 78,00 & 13,57 & 30,00 & 38,46 \\
\hline Pergo & Proficional & & & 68,50 & 7,23 & & \\
\hline Sprella & Derby 9000 & & & & & & \\
\hline Sprella & Derby 12000 & & & & & & \\
\hline Sprella & Derby 24000 & & & & & & \\
\hline Sprella & Polo & & & & & & \\
\hline
\end{tabular}

Um Valor: Apenas uma empresa vende o produto, não sendo possível calcular o Coeficiente de Variação (CV).

** Sem Variação: Todas as empresas que vendem este modelo têm o mesmo preço.

*** Variação em R R: Preço médio de Setembro menos o Preço médio de Março.

**** Variação em \%. 
Tabela 5 - Listagem dos modelos de pisos de madeira nacionais vendidos nas lojas de Curitiba, preços, média e coeficiente de variação dos preços entre os mês de setembro de 1999 e março de 2000 .

\begin{tabular}{|c|c|c|c|c|c|c|c|}
\hline \multirow{2}{*}{ Fabricante } & \multirow[t]{2}{*}{ Modelo } & \multicolumn{2}{|c|}{ Setembro 1999} & \multicolumn{2}{|c|}{ Março 2.000} & \multicolumn{2}{|c|}{ Variação } \\
\hline & & Média & & Média & C.V. & $* * *$ & ***** \\
\hline Carpiso & & & & 25,00 & * & & \\
\hline Duratex & Home & 23,90 & 6,15 & 41,77 & 5,63 & 17,87 & 42,78 \\
\hline Duratex & Pró & 34,50 & 9,02 & 48,11 & 6,78 & 13,61 & 28,30 \\
\hline Eucatex & Eucapiso & 27,30 & 16,53 & 24,54 & 17,85 & $-2,76$ & $-11,25$ \\
\hline Eucatex & Eucafloor & 38,50 & * & 32,48 & 14,05 & $-6,02$ & $-18,53$ \\
\hline Eucatex & Ellegance & & & 36,98 & 12,21 & & \\
\hline Formiline & Formipiso & & & 40,00 & * & & \\
\hline Inatapiso & & & & 22,00 & * & & \\
\hline Interlínea & & 34,00 & 18,38 & 23,90 & $*$ & $-10,10$ & $-42,26$ \\
\hline Lammy & & & & 27,28 & 9,15 & & \\
\hline Novo Piso & Vilage & 24,05 & * & & & & \\
\hline Novo Piso & Export & 44,50 & 24,40 & 50,00 & ** & 5,50 & 11,00 \\
\hline Novo Piso & Stillo & 34,20 & 7,95 & 32,48 & 4,75 & $-1,73$ & $-5,31$ \\
\hline Novo Piso & Resisten & & & 46,39 & 2,54 & & \\
\hline Ouro Piso & Natural (7mm) & 33,60 & 13,75 & 27,65 & 6,90 & $-5,95$ & $-21,52$ \\
\hline Ouro Piso & Sintético $(7 \mathrm{~mm})$ & 37,33 & 8,96 & 29,90 & * & $-7,43$ & $-24,86$ \\
\hline Poliface & Home & 28,00 & $*$ & 41,63 & 6,77 & 13,63 & 32,74 \\
\hline Poliface & Classic & & & 46,62 & 12,41 & & \\
\hline Poliface & Mariner & & & & & & \\
\hline Trevo piso & Crick & & & 42,00 & * & & \\
\hline Trevo Piso & Classic & 35,00 & ** & 31,63 & 11,62 & $-3,37$ & $-10,66$ \\
\hline Trevo Piso & Trevo Flex & 31,00 & * & 26,97 & 6,64 & $-4,03$ & $-14,96$ \\
\hline Trevo Piso & Export & 29,48 & 4,04 & 44,00 & * & 14,53 & 33,01 \\
\hline Trevo Piso & ATN & 22,45 & 4,56 & 48,50 & 6,41 & 26,05 & 53,71 \\
\hline Trevo Piso & Hitech & 21,00 & 7,56 & 39,50 & 1,79 & 18,50 & 46,84 \\
\hline Trevo Piso & Top Line & 32,00 & * & & & & \\
\hline Trevo Piso & AR & 46,00 & 16,06 & 37,69 & 4,13 & $-8,31$ & $-22,05$ \\
\hline
\end{tabular}

$\mathrm{m}$ Valor: Apenas uma empresa vende o produto, não sendo possível calcular o Coeficiente de Variação (CV).

** $\quad$ Sem Variação: Todas as empresas que vendem este modelo tem o mesmo preço.

*** Variação em R \$: Preço médio de Setembro menos o Preço médio de Março.

**** Variação em \%.

\section{Distribuição}

As empresas estão mais concentradas nos bairros contíguos ao centro da cidade, principalmente nos de maior poder aquisitivo ou próximos a vias de fácil acesso, dentre as regiões com maior concentração estão: Batel, Rebouças, Água Verde e Juvevê, Centro Cívico, São Francisco.
No ano de 1997, existiam cerca de 42 lojas comercializando pisos laminados. Em 1998, foram abertas aproximadamente 9 novas lojas e fecharam 11, restando 40 lojas. Finalmente em 1999 foram abertas 10 novas lojas e outras 3 foram fechadas. Atualmente existem em torno de 47 lojas que vendem pisos laminados, conforme tabela 6 . 
Tabela 6 - Número de Total de Lojas de Pisos de Madeira, Número de Lojas Novas e de Lojas Fechadas Durante 1997, 1998 e 1999, em Curitiba.

\begin{tabular}{c|c|c|c}
\hline ANO & TOTAL DE LOJAS & LOJAS NOVAS & LOJAS FECHADAS \\
\hline 1997 & 42 & 9 & 11 \\
1998 & 40 & 10 & 3 \\
1999 & 47 & 9 & \\
\hline
\end{tabular}

Os clientes interessados em pisos de madeira, são em geral $85 \%$ particulares, $10 \%$ profissionais do ramo (decoradores, arquitetos, engenheiros) e $5 \%$ empresas de construção civil. Dentre os particulares, $40 \%$ são mulheres (casadas ou não), $40 \%$ são casais, $20 \%$ são homens. Estes clientes possuem mais de 25 anos e menos de 50 anos.

Os vendedores são peça fundamental das empresas, as demonstrações e explicações são feitas por eles, os quais controlam preços, descontos, prazos de pagamentos, após isto um orçamentista vai ao local da instalação e fecha o preço da obra. Este orçamento retorna à loja onde o cliente faz o pagamento, e após de 3 a 8 dias, os pisos chegam ao local onde serão colocados, quando são retirados das caixas para no dia seguinte ser iniciada a instalação. O prazo para todo este processo é de 7 a 10 dias após o fechamento do orçamento.

As fábricas em geral oferecem cursos para instaladores, os quais duram em geral um final de semana ou três dias. Algumas fábricas fazem cursos de reciclagem pelo lançamento de um novo produto ou mudança considerável nos padrões de seus produtos. Em alguns casos a própria empresa comercial realiza cursos de atualização para seus instaladores (em geral as empresas grandes, $20 \%$ do total das empresas).

As empresas maiores $\mathrm{e}$ as que trabalham com pisos importados possuem depósito próprios, com $500 \mathrm{~m}^{2}$ a $4.000 \mathrm{~m}^{2}$ de pisos, mantendo um funcionário responsável pelo gerenciamento do estoque.

O transporte do material para o local da instalação, ocorre nas empresas médias e grandes utilizando veículos próprios das empresas. O transporte do instalador, em $60 \%$ das situações é de sua própria responsabilidade.

É comum empresas trabalharem com um ou dois veículos de carga de pequeno porte (até 4 ton), e dependendo da quantidade de vendas, existem empresas com até dois caminhões para transportes em geral.

\section{Promoção}

Aos clientes são oferecidos, em geral, atrativos adicionais para promover às vendas. Em termos de conforto, $50 \%$ das empresas não oferecem estacionamento próprio, as demais utilizam estacionamentos nas próprias lojas ou estacionamentos comuns (shopping).

Apenas uma empresa das entrevistadas, planejava o uso de brinde pela compra de produtos; nenhuma empresa realiza promoções cruzada (uso de uma marca para divulgar outra marca não concorrente); entre as empresas grandes e médias é comum o uso de descontos na compra de acessórios de acabamento (promoções vinculadas); é comum entre todas as empresas o feitio de orçamentos sem compromisso. Quanto aos descontos, ou são promocionais (por tempo limitado e para todos os clientes) ou são por quantidade vendida e assiduidade do cliente, mas nunca passam $10 \%$ do valor de venda.

O uso de prazos de pagamento é a prática mais comum entre as empresas, em geral ficando em uma entrada mais três parcelas mensais referentes ao preço a vista sem desconto (usado por $70 \%$ das empresas) ou uma parcela mais quatro (usado por $30 \%$ ).

Para algumas empresa (50\%), é comum a participação em pelo menos uma feira de negócios por ano (feira do Lar, feira do Mobiliário), outros 25\% das empresas participam de mais de uma feiras por ano e o restante (25\%), não participa de feiras. Quanto a participação nestas feiras, em geral, o estande é atendido pelos próprios empregados da empresa, dispensando serviços de demonstradores e de recepcionistas.

Todas as empresas de Curitiba pesquisadas utilizam em suas lojas, os estandes e panfletos de propaganda distribuídos pelas fábricas de pisos, nas empresas médias e grandes o atendimento ao cliente é feito pessoalmente por um vendedor em salas próprias. 
Determinadas empresas adotam posturas mais agressivas quanto à propaganda vinculada em meios de comunicação, 30\% das empresas (em geral as grandes e médias) estão associadas a alguma agência de propaganda, escolhendo o jornal e revista especializadas como o principal meio, seguido pela televisão, painéis publicitários e rádio, estes últimos são mais utilizados quando há promoção especiais nas lojas.

Conforme o estipulado pelo código do consumidor, as fábricas de pisos de madeira devem fornecer garantia de qualidade $\mathrm{e}$ assistência técnica por um prazo determinado de 5 anos, em geral as garantias são maiores ficando entre 5 e 10 anos para pisos com lâmina de madeira e de 10 a 20 anos para pisos com lâmina melamínicas (Alto Tráfego). As empresas também fornecem garantias para os seus serviços de instalação mas estas tem uma maior variação.

\section{Conclusão}

Um dos pontos mais característicos, no mercado de pisos de madeira é a existência de muitos modelos de produtos, sendo que estes tem em essência a mesma função, mas possuem características diferenciadas, dificultando a escolha por parte do usuário.

Em geral, os pisos importados possuem um revestimento sintético, sendo assim mais resistentes e mais caros que os pisos laminados nacionais.

Dentre os pisos importados há predominância pelas empresas européias.

O mercado de pisos apresenta uma sazionalidade, a qual é percebida pela diminuição nas vendas durante os meses de Janeiro, Fevereiro, Junho e Julho, bem como o aumento das vendas a partir de Setembro até Dezembro.

Ao longo de seis meses, alguns pisos de madeira laminada nacionais tiveram grandes alterações nos seus preços, chegando a aumentos de até $53,71 \%$, decorrente de ajustes econômicos, como também ocorreram reduções de até $42,26 \%$, sendo que estas reduções em geral são explicadas por questões administrativas e estratégias de mercado dos seus fabricantes.

$\mathrm{O}$ preço dos pisos nacionais de primeira qualidade (não levando em conta modelos ou custo de produção), varia em torno de $44 \%$. Os pisos importados de primeira qualidade (não levando em conta modelos o custo de produção), tem uma amplitude de preço de $41 \%$.

Para determinados produtos, há no mercado o comércio de material de segunda linha e este pode ter reduções no preço de até $20 \%$ em relação ao produto de primeira linha.

Existem produtos com o mesmo preço em diferentes empresas, podendo indicar uma política de preço controlado, por parte do fabricante para com os seus revendedores.

Curitiba conta (março de 2000) com 47 pontos de venda de pisos, em dois anos ocorreu uma entrada de 19 empresas e uma saída de 14 empresas.

É possível encontrar uma concentração de empresas em dois pontos da cidade, em regiões que apresentam alto poder aquisitivo.

O perfil do consumidor final é o do público feminino, casado, renda familiar acima de

R\$ 1.500,00/ mês, em geral com bom nível cultural, entre 25 e 50 anos. Desta forma, lojas com pessoal bem treinado, técnicas de venda voltadas ao público feminino, salas de atendimento individualizado, pontualidade nas interações com o cliente (data do orçamento, data do início e fim da obra, etc.), dentre outras atitudes, podem ser itens observáveis para o aumento nas vendas.

A preparação dos instaladores se dá por cursos da própria fábrica, e pelo aprendizado com colocadores mais experientes, mas ainda é sentido uma certa carência técnica destes, seja no equipamento utilizado ou na prática adquirida.

Uma prática bastante utilizada é a venda a prazo. Outras vantagens ao cliente, no sentido de atrair e promover as vendas não são muito comuns, em geral elas não passam muito das promoções usuais encontradas no comércio em geral.

Finalmente, pode-se propor que os comerciantes de pisos laminados tenham maior interesse em conhecer novas ferramentas de vendas através de técnicas de Marketing.

\section{BIBLIOGRAFIA CITADA}

\section{CASA CLAUDIA. 2000. Por que escolher o piso laminado. Editora Globo, Março, pag $74-76$.}


CESA, E. T.; SINCLAIR S. A. 1988. Hardwood specialty products: a billion dollar product line for home center retailers. Forest products journal. Madison. Vol. $38 ; \mathrm{n}^{\circ} 6$.

GANGNON, M. A. ADAMS R. D. 1999. A marketing profile of the U.S. structural insulated panel industry. Forest products journal. Madison. Vol. 49; $\mathrm{n}^{\text {o. }} 7 / 8$.

HAMMETT, A. L. 1998. Distribubution. A workshop in forest products marketing. DWSFP/ CFWR. Blacksburg.

MEDEIROS, H. 1995. A evolução da espécie. Techne. Vol 3; n $^{\text {. }}$ 15; São Paulo;

MOTTA, N. F. 1994. Pesquisa de marketing. $2^{a}$ ed. São Paulo; Atlas. 350.

NAGLE, T. T.; HOLDEN, R. K. 1995. The strategy and tactics of pricing. $2^{\text {a. }}$ Ed. NJ. E. cliffs: Prentice Hall.
KOTLER, P. 1998. Administração de marketing: Análise, planejamento, implantação e controle. 5. ed. São Paulo: Atlas,.

SINCLAIR, S. A. 1992. Forest products marketing. New York. Mcgraw-hill.

SINDUSCON-PR, 2000. Pesquisa sobre preferências e tendências de consumidores de casas e apartamentos na região metropolitana de Curitiba, SINDUSCON-PR, circulação interna, p. 45 a 47.

SMITH, R. L. 1998. Pricing. A workshop in forest products marketing. DWSFP/ CFWR. Blacksburg.

VEIGA, M. G. 1997. Como construir: Pisos de madeira. Techne. São Paulo. Vol. 5, n ${ }^{0} 28$.

VLOSKY, R. 1999. Ebusiness in forest products industry. Forest products journal. Madison. Vol. 49; $\mathrm{n}^{\mathrm{o}} \quad 10$. 